\title{
Biosynthèse des protéines par des bactéries et des moisissures cultivées sur milieu de lactosérum
}

\author{
par \\ W. BEDNARSKI, J. JAKUBOWSKI, S. POZNANSKI \\ et A. SURAZYNSKI \\ (Institut du Génie et de la Biotechnologie Alimentaire. \\ Université Agricole d'Olsztyn - Pologne)
}

\section{Introduction}

Au cours des dernières années un intérêt de plus en plus vif s'est manifesté pour la production de protéines par la biosynthèse biologique, en utilisant des algues, des moisissures et des levures. La demande de protéines pour la nutrition et l'affouragement augmente de plus en plus et nous force de chercher des réserves de matière première qui pourrait servir de substrat pour une telle biosynthèse.

Dans nos expériences, nous avons résolu de faire usage d'un substrat bien peu coûteux, tel que le lactosérum sous-produit de la production des fromages et des quarks, pour la biosynthèse des protéines à utiliser comme fourrage, en forme de biomasse de moisissures, ou bien de biomasse mixte de bactéries et de moisissures.

\section{Protocole expérimental}

Dans nos expériences, les espèces suivantes de moisissures étaient employées : Penicillium roqueforti WR-16, Oospora lactis 15, Zygorrhynchus meelleri LECK-81, Rhizopus oligosporus CBS 33962.

Pour la biosynthèse des protéines, le lactosérum complètement déprotéiné était employé. Notre but était d'utiliser le lactosérum, après avoir séparé complètement les combinaisons azotées du lait ou du lactosérum.

Le lactosérum était stérilisé à l'autoclave à $100^{\circ} \mathrm{C}$ pendant $15 \mathrm{mn}$. Après stérilisation, le milieu était additionné de 0,3 p. $100 \mathrm{KH}_{2} \mathrm{PO}_{4}$; 0,05 p. $100 \mathrm{MgSO}_{4} .7 \mathrm{H}_{2} \mathrm{O}$; 0,02 p. $100 \mathrm{MnSO}_{4} .5 \mathrm{H}_{2} \mathrm{O}$; 0,002 p. $100 \mathrm{ZnHPO}_{4}$, ainsi que de sources d'azote sous forme de sels azotiques. 
Le milieu était ensemencé avec 10 p. 100 d'inoculum de la culture mère en question (par rapport au poids). La culture était développée dans des bouteilles de Roux à $27^{\circ} \mathrm{C}$ pendant $96 \mathrm{~h}$, le renouvellement continu de l'air étant entretenu dans les bouteilles.

A la première étape de l'expérimentation on déterminait les quantités optimales des combinaisons azotiques, tels que le nitrate d'ammonium, le phosphate d'ammonium, le sulfate d'ammonium et l'urée, qui devaient être ajoutés au milieu. La culture témoin de moisissures était développée sur le même milieu de lactosérum non additionné de combinaisons azotées. De toutes ces combinaisons, c'est l'urée qui s'est montré le plus convenable.

La dose la plus effective d'urée était déterminée de la manière suivante. Le milieu de lactosérum était préparé, additionné de 0,2 p. $100,0,4$ p. $100,0,6$ p. $100,0,8$ p. 100 et 1 p. 100 d'urée, et la culture de moisissures était développée dans les conditions précédemment décrites.

L'influence des paramètres technologiques sur le rendement de la biosynthèse des protéines effectuée par des moisissures était déterminée de la manière suivante :

a) L'acidité était ajustée aux $\mathrm{pH}$ de 4,$5 ; 5,0 ; 6,0 ; 6,5$ et 7,0 , les autres paramètres de la culture demeurant inchangés.

b) La température d'environnement et le temps de la culture étaient établis en faisant croître la culture à trois températures différentes : $18^{\circ} \mathrm{C}, 25^{\circ} \mathrm{C}$ et $32^{\circ} \mathrm{C}$.

La température de $25^{\circ} \mathrm{C}$ ayant été trouvée la plus convenable pour la synthèse des protéines par les moisissures, on a essayé d'établir le temps optimum de la culture dans ces conditions. L'accroissement de la biomasse de moisissures était observé après 2-4-5 et $6 \mathrm{j}$.

Des bactéries Lactobacillus helveticus, Propionibacterium shermani ou $E$. coli étaient cultivées de la manière décrite dans nos travaux sur le problème en question (Bednarski et al., 1970, 1971).

La biomasse de moisissures, ou celle de bactéries et de moisissures était séparée par centrifugation, $4000 \mathrm{t} / \mathrm{mn}$ pendant $15 \mathrm{mn}$. La biomasse obtenue était séchée à $70^{\circ} \mathrm{C}$ jusqu'à poids constant.

\section{Méthodes analytiques}

Avant et après la culture des micro-organismes, la teneur du milieu en azote total était déterminée par la méthode de Kjeldahl, la teneur en azote aminé par le procédé courant, la teneur en urée d'après Owsiejczuk (1967) et celle en sucres réducteurs d'après Bertrand.

La teneur de la biomasse en extrait sec et en protéines totales était déterminée par la méthode de Kjeldahl $(\mathrm{N} \times 6,25)$. La teneur 
en acides nucléiques de la biomasse de moisissures était déterminée à l'aide de la méthode de Shmidt et Tannhauser (Brzeski et Kaniuga, 1957). La détection des antibiotiques (substances inhibant le développement des bactéries) était effectuée par la méthode de diffusion (Yeroussalimskiy et al., 1959), en se servant d'une souche de Bacillus subtilis et d'Escherichia coli. Les résultats étaient exprimés en unités internationales de pénicilline. La teneur en vitamines $B_{1}$ et $B_{2}$ était déterminée par la méthode de fluorimétrie (Nesterova, 1967).

La composition quantitative des acides aminés était déterminée par la méthode d'électrophorèse à haute tension et par l'électrochromatographie (Maslowski, 1957, 1960). A la base de la composition déterminée d'acides aminés, contenus dans la biomasse de moisissures et dans la biomasse mixte de bactéries et de moisissures, l'indice d'acides aminés d'après Oser était calculé (Armstrong et Mittchel, 1955).

\section{Résultats}

Dans le cas de la culture additionnée de combinaisons azotées, le rendement en protéines de mycélium était plusieurs fois plus élevé en comparaison avec la culture de moisissure témoin. Dans des cultures additionnées du phosphate bibasique d'ammonium, des quantités élevées de protéines étaient obtenues, montant de 0,67 à $0,99 \mathrm{~g}$ à partir de $100 \mathrm{~g}$ du milieu.

De bons résultats étaient aussi obtenus dans le cas de la culture qui contenait l'urée comme source d'azote. La quantité des protéines synthétisées à partir de $100 \mathrm{ml}$ du milieu additionné d'urée montait de 0,55 jusqu'à $0,97 \mathrm{~g}$, conformément à l'espèce de moisissure étudiée. L'augmentation de la biomasse et des protéines synthétisées était moins élevée dans le milieu additionné de nitrate d'ammonium et les quantités les moins élevées de protéines étaient obtenues sur le milieu où le sulfate d'ammonium était la source de l'azote minéral.

Pour déterminer la dose optimale de la source d'azote, l'urée seule était employée. Cette combinaison a été choisie à cause de son prix d'achat qui est plusieurs fois moins élevé que celui du phosphate d'ammonium. Des essais qu'on a fait sur la dose optimale d'azote en forme d'urée il résulte que l'addition de 0,4 p. 100 au milieu de lactosérum s'est montrée suffisante.

En continuant notre expérimentation nous avons constaté que les quantités de protéines qui étaient synthétisées par des moisissures cultivées sur le milieu de lactosérum dépendaient de la température et de la durée de la culture, et, à un degré moins élevé, de l'acidité initiale du milieu. Les moisissures essayées se sont montrées bien tolérantes envers l'acidité active variant entre $\mathrm{pH} 4,5$ et 7,0 (tab. 1). 
TABLEAU 1. - Sorte et quantité des combinaisons azotées et rendement de la biosynthèse des protéines par des moisissures Teneur en extrait sec et en protéines du mycélium exprimée en $\mathrm{g} / 100 \mathrm{ml}$

\begin{tabular}{|c|c|c|c|c|c|c|c|c|c|}
\hline \multirow{2}{*}{$\begin{array}{c}\text { Milieu } \\
\text { fondamental } \\
\text { de } \\
\text { lactosérum }\end{array}$} & \multirow{2}{*}{$\begin{array}{l}\text { Quantité de } \\
\text { combinaisons } \\
\text { azotées } \\
\text { ajoutées } \\
\text { p. } 100\end{array}$} & \multicolumn{4}{|c|}{ Extrait sec } & \multicolumn{4}{|c|}{ Protéines } \\
\hline & & O. lactis & $\begin{array}{l}\text { R. oligo- } \\
\text { sporus }\end{array}$ & Z. meelleri & $\begin{array}{l}\text { P. roque- } \\
\text { forti }\end{array}$ & O. lactis & $\begin{array}{l}\text { R. oligo- } \\
\text { sporus }\end{array}$ & Z. meelleri & $\begin{array}{l}\text { P. roque- } \\
\text { forti }\end{array}$ \\
\hline $\begin{array}{l}\text { Non additionné des sels } \\
\text { azotés } \ldots \ldots \ldots \\
\ldots\end{array}$ & - & 1,22 & 0,96 & 0,95 & 1,00 & 0,20 & 0,21 & 0,18 & 0,16 \\
\hline $\begin{array}{l}\text { Phosphate } \\
\mathrm{NH}_{4} /{ }_{2} \mathrm{HPO}_{4}\end{array}$ & 1 & 1,61 & 1,15 & 1,75 & 1,72 & 0,84 & 0,67 & 0,99 & 0,76 \\
\hline 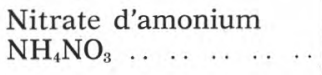 & 1 & 2,05 & 1,35 & 1,11 & 1,40 & 0,67 & 0,47 & 0,38 & 0,62 \\
\hline 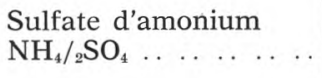 & 1 & 1,50 & 1,23 & 1,22 & 1,41 & 0,48 & 0,39 & 0,50 & 0,47 \\
\hline $\begin{array}{cccccc}\text { Urée } & & & & & \\
\mathrm{NH}_{2} /{ }_{2} \mathrm{CO} & \ldots & \ldots & \ldots & \ldots & \ldots \\
》 & \ldots & \ldots & \ldots & \ldots & \ldots \\
» & \ldots & \ldots & \ldots & \ldots & \ldots \\
» & \ldots & \ldots & \ldots & \ldots & \ldots \\
» & \ldots & \ldots & \ldots & \ldots\end{array}$ & $\begin{array}{l}1 \\
0,8 \\
0,6 \\
0,4 \\
0,2\end{array}$ & $\begin{array}{l}2,27 \\
1,99 \\
2,19 \\
2,39 \\
1,92\end{array}$ & $\begin{array}{l}1,32 \\
1,33 \\
1,49 \\
1,77 \\
1,16\end{array}$ & $\begin{array}{l}1,61 \\
1,51 \\
1,72 \\
1,88 \\
1,53\end{array}$ & $\begin{array}{l}1,84 \\
1,67 \\
1,68 \\
1,88 \\
1,12\end{array}$ & $\begin{array}{l}0,96 \\
0,81 \\
0,93 \\
1,01 \\
0,74\end{array}$ & $\begin{array}{l}0,55 \\
0,74 \\
0,70 \\
0,92 \\
0,47\end{array}$ & $\begin{array}{l}0,84 \\
0,69 \\
0,87 \\
0,81 \\
0,50\end{array}$ & $\begin{array}{l}0,72 \\
0,65 \\
0,68 \\
0,71 \\
0,40\end{array}$ \\
\hline
\end{tabular}


TABLEAU 2. - Influence de la durée de la culture des moisissures sur le rendement de la biosynthèse des protéines Teneur en extrait sec et en protéines exprimée en $\mathrm{g} / 100 \mathrm{ml}$

\begin{tabular}{|c|c|c|c|c|c|c|c|c|}
\hline \multirow{2}{*}{$\begin{array}{c}\text { Durée } \\
\text { de la culture } \\
\text { (en jours) }\end{array}$} & \multicolumn{4}{|c|}{ Extrait sec } & \multicolumn{4}{|c|}{ Protéines } \\
\hline & O. lactis & $\begin{array}{l}\text { R. oligo- } \\
\text { sporus }\end{array}$ & Z. meelleri & $\begin{array}{l}\text { P. roque- } \\
\text { forti }\end{array}$ & O. lactis & $\begin{array}{c}R . \text { oligo- } \\
\text { sporus }\end{array}$ & Z. meelleri & $\begin{array}{l}\text { P. roque } \\
\text { forti }\end{array}$ \\
\hline 2 & 1,27 & 1,42 & 1,78 & 1,63 & 0,55 & 0,67 & 0,76 & 0,63 \\
\hline 4 & 2,41 & 1,58 & 1,93 & 2,03 & 0,96 & 0,66 & 0,83 & 0,75 \\
\hline 5 & 1,97 & 1,62 & 2,12 & 1,91 & 0,78 & 0,69 & 0,85 & 0,67 \\
\hline 6 & 2,02 & 1,93 & 2,31 & 2,13 & 0,81 & 0,75 & 0,94 & 0,72 \\
\hline
\end{tabular}


Le tableau 2 représente l'influence de la durée de la culture des moisissures sur la quantité des protéines synthétisées. On a constaté que les moisissures examinées synthétisaient des protéines tout le temps de la culture, de 2 à $6 \mathrm{j}$. C'est pourtant la cinétique de ce procédé qui mérite un intérêt particulier. A partir du quatrième jour de la culture, de grandes quantités de biomasse étaient produites, qui étaient pourtant moins riches en protéines. En considérant les raisons économiques, il apparaît que la période de $4 \mathrm{j}$ constitue un optimum. On a constaté que la teneur en protéines de la biomasse de moisissures dépendait de la température à laquelle le procédé était réalisé.

Les quantités les plus élevées des protéines synthétisées étaient obtenues dans des cultures développées à la température de $25^{\circ} \mathrm{C}$. Les quantités de protéines qui étaient produites dans des cultures de moisissures à $18^{\circ} \mathrm{C}$ et à $32^{\circ} \mathrm{C}$ étaient de $30 \mathrm{p} .100$, en moyenne moins élevées, par comparaison avec la quantité des protéines qui étaient obtenues dans des cultures de moisissures à $25^{\circ} \mathrm{C}$ (tab. 3).

Le tableau 4 représente les résultats qui caractérisent l'influence de la culture préalable des bactéries sur la culture de lactosérum, exercée sur le rendement de la biosynthèse des protéines par des moisissures. On a constaté que le rendement de la synthèse des protéines était influencé d'une manière essentielle par la culture préalable de Propionibacterium shermanii ou bien par celle d'Escherichia coli.

Selon l'espèce de la moisissure, l'accroissement des protéines synthétisées après la culture de $P$. shermanii était de 16,3 à 95 p. 100, comparé avec la quantité de protéines dans la biomasse produite à partir des moisissures seulement. De même, l'accroissement de la quantité de protéines dans la biomasse composée d'E. coli et des moisissures examinées était de 11,2 à 11,4 p. 100, en comparaison avec la biomasse de moisissures. L'aspect additionnel du procédé de la biosynthèse associée des bactéries et des moisissures cultivées sur le milieu de lactosérum est l'utilisation intensifiée des sucres réducteurs contenus dans le milieu. Au cours de la biosynthèse effectuée par des bactéries et des moisissures, cette utilisation des sucres réducteurs montait en moyenne à 82 p. 100 par rapport à la valeur initiale. Elle était de 30 p. 100 plus élevée que l'utilisation des sucres au cours de la biosynthèse par des moisissures seules.

L'étude de la composition des acides aminés du mycélium a fait conclure que les acides aminés du mycélium étaient du même genre chez toutes les moisissures étudiées. Des différences essentielles se manifestent dans la composition quantitative des acides aminés divers.

L'analyse des résultats obtenus, rassemblés dans le tableau 5, aussi superficielle qu'elle soit, nous permet déjà de constater des différences essentielles dans la composition des acides aminés indis- 


\section{TABLEAU 3}

Influence de la température de la culture des moisissures sur le rendement de la biosynthèse des protéines du mycélium

Teneur en extrait sec et en protéines exprimée en g/100 ml

\begin{tabular}{|c|c|c|c|c|c|c|c|c|}
\hline \multirow{2}{*}{$\begin{array}{l}\text { Température } \\
\text { de la culture } \\
\text { en }{ }^{\circ} \mathrm{C}\end{array}$} & \multicolumn{4}{|c|}{ Extrait sec } & \multicolumn{4}{|c|}{ Protéines } \\
\hline & O. lactis & $\begin{array}{l}\text { R. oligo- } \\
\text { sporus }\end{array}$ & Z. meelleri & $\begin{array}{l}\text { P. roque- } \\
\text { forti }\end{array}$ & O. lactis & $\begin{array}{l}R \text {. oligo- } \\
\text { sporus }\end{array}$ & Z. meelleri & $\begin{array}{l}\text { P. roque- } \\
\text { forti }\end{array}$ \\
\hline $18^{\circ} \mathrm{C}$ & 1,17 & 1,15 & 1,50 & 1,70 & 0,56 & 0,54 & 0,64 & 0,61 \\
\hline $25^{\circ} \mathrm{C}$ & 1,97 & 1,72 & 2,02 & 2,82 & 0,82 & 0,89 & 0,98 & 0,71 \\
\hline $32^{\circ} \mathrm{C}$ & 1,27 & 1,42 & 1,37 & 1,19 & 0,52 & 0,72 & 0,62 & 0,47 \\
\hline
\end{tabular}


TABLEAU 4. - Comparaison du rendement de la biosynthèse des protéines à partir de la culture des moisissures et de la culture mixte des bactéries et des moisissures

Teneur en extrait sec et en protéines du mycélium exprimée en g/100 ml

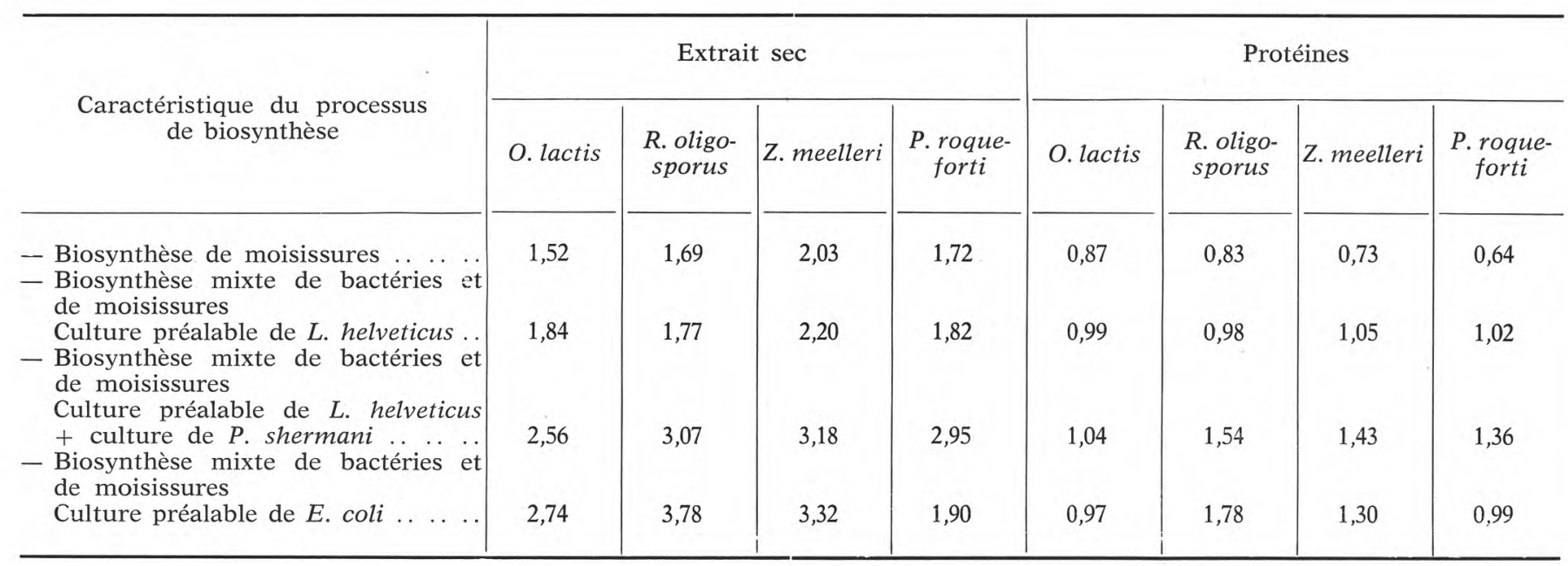


TABLEAU 5. - Teneur en acides aminés indispensables, et à demi-indispensables, de la biomasse de moisissures et de la biomasse mixte de bactéries et de moisissures, obtenues sur le milieu de lactosérum pris en considération pour le calcul de l'index d'Oser

Teneur en acides aminés exprimée en $\mathrm{g} / 16 \mathrm{~g} \mathrm{~N}$

\begin{tabular}{|c|c|c|c|c|c|c|c|c|c|}
\hline \multirow[b]{2}{*}{ Acides aminés } & \multirow{2}{*}{$\begin{array}{c}\text { Oeuf de poule } \\
\text { étalon de FAO } \\
\text { (1968) }\end{array}$} & \multicolumn{4}{|c|}{ Biomasse de moisissures } & \multicolumn{4}{|c|}{ Biomasse mixte de bactéries et de moisissures } \\
\hline & & $\begin{array}{l}P . \text { roque- } \\
\text { forti }\end{array}$ & $\begin{array}{l}\text { R. oligo- } \\
\text { sporus }\end{array}$ & $\begin{array}{l}\text { Oospora } \\
\text { lactis }\end{array}$ & Z. meelleri & $\begin{array}{c}\text { E. coli } \\
+P . \text { roque- } \\
\quad \text { forti }\end{array}$ & $\begin{aligned} & \text { E. coli } \\
&+ \text { R. oligo- } \\
& \text { sporus }\end{aligned}$ & $\begin{aligned} & E . \text { coli } \\
&+O . \text { lactis }\end{aligned}$ & $\begin{array}{l}\text { E. coli } \\
+ \text { Z. meel- } \\
\quad \text { leri }\end{array}$ \\
\hline $\begin{array}{llllll}\text { Lysine } & . & \ldots & \ldots & \ldots & . .\end{array}$ & 6,4 & 5,1 & 5,4 & 7,1 & 8,3 & 8,2 & 9,0 & 8,6 & 8,5 \\
\hline Histydine $\quad . . \quad \ldots \quad . . \quad .$. & 2,4 & 2,8 & 2,6 & 2,8 & 2,7 & 2,8 & 2,8 & 2,8 & 2,7 \\
\hline Phénylalanine $\ldots$.. .. & 5,8 & 6,4 & 6,3 & 4,6 & 5,9 & 6,6 & 6,6 & 6,4 & 6,4 \\
\hline Tyrosine $\ldots \ldots \ldots \ldots$ & 4,2 & 4,6 & 5,0 & 4,5 & 4,7 & 5,3 & 6,0 & 4,9 & 4,9 \\
\hline Tryptophane .. .. . . & 1,6 & 1,0 & 1,0 & 1,2 & 1,1 & 2,0 & 2,5 & 1,8 & 1,6 \\
\hline Méthionine $\ldots \ldots \ldots$ & 3,1 & 1,6 & 2,0 & 1,7 & 1,7 & 2,0 & 2,5 & 1,9 & 2,5 \\
\hline $\begin{array}{llllll}\text { Cystine } & \ldots & \ldots & \ldots & \ldots & \ldots\end{array}$ & 2,4 & 1,3 & 1,6 & 1,3 & 1,2 & 1,4 & 1,7 & 1,4 & 1,4 \\
\hline $\begin{array}{lllll}\text { Thréonine } & \ldots & \ldots & \ldots & \ldots\end{array}$ & 5,1 & 4,9 & 4,6 & 5,0 & 4,7 & 5,5 & 6,3 & 6,0 & 5,2 \\
\hline Isoleucine + leucine.. & 15,4 & 16,2 & 17,0 & 17,7 & 16,9 & 15,0 & 17,1 & 17,8 & 16,9 \\
\hline $\begin{array}{llllll}\text { Valine } & \ldots & \ldots & \ldots & \ldots & \ldots\end{array}$ & 7,3 & 5,9 & 7,3 & 6,4 & 7,1 & 7,3 & 7,7 & 7,8 & 7,2 \\
\hline $\begin{array}{l}\text { Index d'Oser d'après } \\
\text { Armstrong et Mittchell }\end{array}$ & 100 & 83,0 & 88,1 & 87,5 & 88,8 & 94,7 & 97,1 & 95,0 & 96,2 \\
\hline
\end{tabular}


pensables dans les mycéliums étudiés, en faveur de la biomasse mixte de bactéries et de moisissures. De tous les acides aminés, c'était dans le cas du tryptophane que l'on a constaté l'accroissement le plus élevé de la quantité après la biosynthèse mixte des bactéries et des moisissures, par rapport à la biosynthèse due à des moisissures seules. Dans la biomasse d'E. coli et des moisissures respectives, cet accroissement montait de 40 jusqu'à 130 p. 100. L'accroissement de la teneur en lysine de la biomasse à partir de la culture E. Coli-R. oligosporus était de 67 p. 100 et dans le cas de E. coli$P$. roqueforti, il montait à 60 p. 100 environ. Dans la biomasse à partir de la biosynthèse mixte de bactéries et de moisissures, on observait aussi la teneur augmentée d'un acide aminé limitant, la méthionine, qui variait de 10 à 30 p. 100 . On doit noter aussi l'accroissement élevé de la teneur en autres acides aminés, tels que l'arginine, la phénylalanine, la thréonine et la tyrosine, qui augmentent de 21 à 52 p. 100, en comparaison avec la teneur en ces acides aminés de la biomasse de moisissures seules. Les résultats obtenus parlent en faveur de la biosynthèse des protéines à la base de la culture préalable d'E. coli, en raison du rendement élevé de ce procédé et de la teneur plus élevée en acides aminés indispensables.

A la base de l'indice d'Oser, la valeur biologique était calculée pour des biomasses de moisissures particulières, savoir : 83 pour $P$. roquefort $i-88,1$ pour $R$. oligosporus $-87,5$ pour $O$. lactis et 88,8 pour Z. meelleri. Pour des biomasses mixtes de bactéries et de moisissures, on a observé une augmentation importante de la valeur biologique, calculée avec l'indice d'Oser. Ainsi cette valeur augmentait jusqu'à 94,7 , c'est-à-dire 14 p. 100 pour $E$. coli- $P$. roqueforti, jusqu'à $97 / 10,8$ p. 100 pour $E$. coli-R. oligosporus, jusqu'à $95 / 9,7$ p. 100 pour E. coli-O. lactis, et jusqu'à $96,2 / 9,1$ p. 100 pour $E$. coli-Z. meelleri, par rapport à la valeur qui était calculée pour la biomasse de la moisissure correspondante. Outre l'indice d'Oser élevé, la biomasse mixte de bactéries et de moisissures se caractérisait par des teneurs élevées en vitamines $\mathrm{B}_{1}$ et $\mathrm{B}_{2}$.

\begin{tabular}{l|c|c}
\hline & $\mathrm{B}_{1}$ & $\mathrm{~B}_{\mathrm{g}}$ \\
\hline & & \\
E. coli + Rhizopus oligosporus. & $6,4 \mu \mathrm{g} / \mathrm{g}$ & $30,0 \mu \mathrm{g} / \mathrm{g}$ \\
E. coli + Zygorrhynchus meelleri & $13,5 \mu \mathrm{g} / \mathrm{g}$ & $46,5 \mu \mathrm{g} / \mathrm{g}$ \\
E.coli + Oospora lactis ....... & $38,8 \mu \mathrm{g} / \mathrm{g}$ & $50,0 \mu \mathrm{g} / \mathrm{g}$ \\
E. coli + Penicillium roqueforti. & $11,7 \mu \mathrm{g} / \mathrm{g}$ & $21,0 \mu \mathrm{g} / \mathrm{g}$ \\
\hline
\end{tabular}

Les teneurs en acides nucléiques des biomasses étudiées sont présentées dans le tableau suivant : 


\begin{tabular}{|c|c|c|c|}
\hline Espèces de micro-organismes & $\begin{array}{c}\text { Teneur } \\
\text { en ARN } \\
\text { p. } 100\end{array}$ & $\begin{array}{c}\text { Teneur } \\
\text { en ADN } \\
\text { p. } 100\end{array}$ & $\begin{array}{c}\text { Total } \\
\text { ARN + ADN } \\
\text { p. } 100\end{array}$ \\
\hline 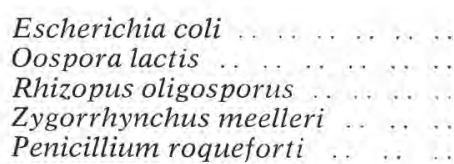 & $\begin{array}{r}10,31 \\
5,80 \\
7,32 \\
5,24 \\
3,95\end{array}$ & $\begin{array}{l}0,87 \\
0,91 \\
0,56 \\
0,84 \\
0,79\end{array}$ & $\begin{array}{r}11,18 \\
6,71 \\
7,88 \\
6,08 \\
4,74\end{array}$ \\
\hline
\end{tabular}

Il en résulte que la teneur en acides nucléiques des germes d'E. coli était la plus élevée. Dans les mycéliums des moisissures étudiées, la teneur en acides nucléiques était moins élevée. Outre cela, on a constaté des quantités minimes de substances qui inhibaient le développement des bactéries, par rapport à l'activité de l'échantillon de pénicilline.

\begin{tabular}{|c|c|c|}
\hline & Avec $B$. subtilis & Avec E. coli \\
\hline 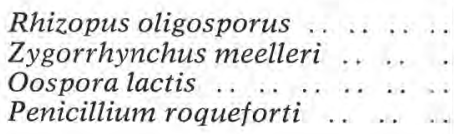 & $\begin{array}{l}0,65 \mathrm{UI} / \mathrm{ml} \\
0,70 \mathrm{UI} / \mathrm{ml} \\
0,55 \mathrm{UI} / \mathrm{ml} \\
0,45 \mathrm{UI} / \mathrm{ml}\end{array}$ & $\begin{array}{c}0,60 \mathrm{UI} / \mathrm{ml} \\
0,75 \mathrm{UI} / \mathrm{ml} \\
0,55 \mathrm{UI} / \mathrm{ml} \\
\text { non constaté }\end{array}$ \\
\hline
\end{tabular}

\section{Discussion}

Des études faites sur la biosynthèse des protéines par des moisissures cultivées sur milieu de lactosérum il est à conclure que l'intensité de ce procédé dépendait avant tout de la forme et de la quantité des combinaisons azotées et phosphorées ajoutées au milieu, ainsi que des paramètres technologiques, tels que la durée de la culture, sa température, et, à un moindre degré, l'acidité initiale du milieu.

Les résultats de nos recherches concordent avec ceux de Bloch (1953) et de Painter (1954).

La culture préalable de souches microbiennes de Propionibacterium shermanii ou de $E$. coli s'est montrée être un facteur essentiel qui intensifiait le processus de la biosynthèse des protéines par les moisissures étudiées. Des bactéries de $P$. shermanii se caractérisaient par leur pouvoir d'utiliser la lactose et le lactate de calcium ainsi que par leur propriété de synthétiser la vitamine $B_{12}$ (Bullerman et Berry, 1966). Pour préparer le milieu au développement intensifié de $P$. shermanii, Lactobacillus helveticus y était précédemment multiplié pour enrichir en acide lactique. Après neutralisation avec de l'oxyde 
de calcium, l'acide lactique constituait un bon substrat pour les bactéries propioniques.

Des souches de bactéries $E$. coli se caractérisent par leur pouvoir de synthétiser de grandes quantités de méthionine, de tryptophane et de valine (Gunsalus et Stanier, 1962). Les souches bactériennes que nous avons cultivées synthétisaient de grandes quantités de biomasse : 0,180 $\mathrm{g} / 100 \mathrm{ml}$ en moyenne, avec une teneur en protéines de 82 p. 100 et de nombreux produits intermédiaires, qui étaient ensuite utilisés par les moisissures cultivées sur le même milieu. De grandes quantités de la biomasse mixte de bactéries et de celles mixtes, de bactéries et de moisissures, que nous avons obtenues à partir de la culture développée dans les conditions du laboratoire, nous ont encouragé à entreprendre l'expérimentation au stade demi-technique, en nous servant des paramètres technologiques précédemment établis pour obtenir la biomasse de bactéries et de moisissures.

Les résultats de ces expériences sont présentés dans le tableau suivant :

\begin{tabular}{|c|c|c|c|c|}
\hline $\mathrm{N}^{\circ}$ & Sortes de biomasse & $\begin{array}{c}\text { Extrait sec } \\
\text { de } \\
\text { mycélium } \\
\text { g/l } \\
\text { du } \\
\text { milieu }\end{array}$ & $\begin{array}{c}\text { Protéines } \\
\text { du } \\
\text { mycélium } \\
\text { g/1 } \\
\text { du } \\
\text { milieu }\end{array}$ & $\begin{array}{c}\text { Utilisation } \\
\text { des sucres } \\
\text { réducteurs. } \\
\text { Pourcentage } \\
\text { de la valeur } \\
\text { initiale }\end{array}$ \\
\hline 1 & E. coli + Oospora lactis & 37,20 & 19,70 & 68,20 \\
\hline 2 & E. coli + Z. meelleri & 29,20 & 12,10 & 65,30 \\
\hline 3 & E. coli $+R$.oligosporus & 47,50 & 23,30 & 62,40 \\
\hline
\end{tabular}

On voit que les quantités de protéines qui étaient produites au cours de la biosynthèse de bactéries et de moisissures au stade demiindustriel, surpassaient bien celles qu'on avait produites dans les conditions du laboratoire dans le cas de la biomasse de $E$. coli $+O$. lactis et de celle de $E$. coli et $R$. oligosporus, ou bien étaient semblables, comme dans le cas de $E$. coli $+Z$. meelleri. Dans des expériences dernièrement effectuées nous avons réussi à obtenir l'utilisation complète du lactose du milieu. En continuant ce procédé de la biosynthèse, on pourra obtenir plus de $2 \mathrm{~kg}$ de protéines à partir de 1001 de milieu. Par exemple, des méthodes modernes permettent de précipiter 3-3,2 $\mathrm{kg}$ de protéines à partir de $100 \mathrm{l}$ de lait. 
Les teneurs en lysine, méthionine et tryptophane, de la biomasse des moisissures que nous avons cultivées ressemblent beaucoup aux teneurs en ces acides aminés des mycéliums de Penicillium, Rhizopus et Zygorrhynchus qui étaient cultivés sur le milieu synthétique par Rhodes et al. (1961). En même temps, elles l'emportaient, par leur composition en acides aminés, sur les mycéliums obtenus au cours de la production des antibiotiques (Janicki et Skupin, 1958).

Par contre, la biomasse mixte de bactéries et de moisissures que nous avons produite, l'emporte sur celle de moisissures seules par sa teneur de la plupart des acides aminés, et surtout par la teneur en ceux qui sont nécessaires. Par leur teneur en acides aminés indispensables, les moisissures que nous avons examinées égalent le blanc de l'œuf de poule. C'est surtout la biomasse mixte de bactéries et de moisissures, en combinaison avec les quatre espèces de moisissures examinées, qui s'était montrée particulièrement riche en les acides aminés en question. Ce n'est que sous le rapport des acides aminés sulfurés, méthionine et cystine, que la biomasse de notre production le cédait au blanc de l'œuf de poule. L'intérêt particulier est dû à la différenciation de la teneur en acides nucléiques des organismes étudiés. Les quantités les plus élevées d'acides nucléiques ont été observées dans la biomasse de E. coli. Parmi les mycéliums, de grandes quantités d'ARN et ADN ont été découvertes dans les moisissures qui se caractérisaient par une grande quantité de protéines dans le mycélium, telles que Rhizopus oligosporus et Oospora lactis. Ces résultats font la preuve de la stricte relation entre la teneur en acides nucléiques dans la cellule des microorganismes et sa prédisposition à la biosynthèse de protéines.

La biosynthèse des protéines, par des bactéries et des moisissures, peut être effectuée avec succès au stade industriel sans dépenses trop élevées, pour obtenir ainsi un rendement élevé en protéines riches en acides aminés indispensables. Les recherches que nous poursuivons sur l'autolyse des cellules, accompagnée de leur hydrolyse, paraissent indiquer que l'utilisation de ces protéines par des organismes animaux serait satisfaisante.

\section{$R$ és u m é}

On a étudié la biosynthèse des protéines par des moisissures : Penicillium roqueforti WR-16, Oospora lactis-15, Zygorrhynchus meelleri LECK-81, Rhizopus oligosporus CBS 33962, cultivées sur milieu de lactosérum.

La culture associée de bactéries $E$. coli et des moisissures permet d'obtenir, dans des conditions optimales, $23 \mathrm{~g}$ de protéines environ à partir de 11 de lactosérum. La biomasse qui était obtenue contenait des quantités relativement élevées d'acides aminés limitants, tels que la méthionine $2-2,5 \mathrm{~g} / 16 \mathrm{~g} \mathrm{~N}$, la lysine 8,5-9 $\mathrm{g} / 16 \mathrm{~g} \mathrm{~N}$ et le tryptophane 1,8-2,5 g/16 $\mathrm{g} \mathrm{N}$. La valeur de l'index 
d'Oser variait de 83-85 pour la biomasse de moisissures et de 95-97 pour la biomasse mixte de bactéries et de moisissures. Outre cela, la teneur élevée en vitamines $B_{1}$ et $B_{2}$ et en acides nucléiques confirme que la biomasse mixte de bactéries et de moisissures est un composant précieux de la ration alimentaire animale.

\section{S u m m a ry}

\section{Protein Biosynthesis by Bacteria and Moulds} when Cultivated on Whey Medium

Studies were conducted on protein biosynthesis by following mould strains : Penicillium roqueforti WR-16, Oospora lactis-15, Zygorrhynchus meelleri LECK-81, Rhizopus oligosporus CBS 33962 which were cultivated on whey medium.

The intensity of this process was found to depend on the quality and amount of nitrogen compounds as added to the medium, as well as on thechnological parameters, such as time and temperature of cultivation. To less extent, it depended on the original acidity of the medium.

The process of protein biosynthesis by moulds appeared to be intensifield by preliminaryly accumulated biomass of Propionibacterium shermani or Escherichia coli which was followed by the cultivation of moulds.

Amounts of proteins which were obtained from whey medium by associated biosynthesis of bacteria and moulds, varied from 12,1. to $23,3 \mathrm{~g} / \mathrm{l}$.

Mixed biomass of moulds and bacteria was characterized by high content of B-vitamins and nucleic acids. Low amounts of bacterial inhibitors were also found to be present in the biomass. The quantitative composition of amino acids depended on mould species and on cultivation procedures.

Biological values for the mould biomass and the mixed biomass of bacteria and moulds were 83-89 and 95-97, respectively. The results of biological values require further affirmation by experiments with animals.

Reçu pour publication en mai 1971.

\section{Bibliographie}

- Armstrong (D. G.) and Mittchel (H. H.) (1955). - Protein nutrion and the utilization of dietary protein at different levels of intake by growing swine. J. Anim. Sci., 14, 49.

- Bednarski (W.), Jakubowski (J.), Poznanski (S.) et Surazynski (A.) (1970). Utilisation de la biosynthèse des bactéries et des moisissures pour enrichir des fourrages des hydrates de carbone en protéines et vitamines. Le Lait, $50,285$. 
- Bednarski (W.), Jakubowski (J.), Poznanski (S.), Surazynski (A.) (1971). Wydajnosc biosyntezy bialka przez plesnie w zaleznosci od warunkow hodowli. Przemysl Spozywczy, 25, 3, 102.

- Block (S. S.), Stearns (T. W.), Stephens (R. L.) and Canddlles (R. F. J.) (1953). - Mushroom mycelium experiments with Submerged culture. J.. Agr. Food. Chem., 14, 890.

- Bullerman (L. B.) and Berry (E. C.) (1966). - Use of Cheese Whey for Vitamines $\mathrm{B}_{12}$ Production. Appl. Microbiol., 14, 355.

- Gunsalen (C.) and Stanier (R. J.) (1962). - The Bacteria. Vol. III. Biosynthesis. Akademic Press., New-York and London.

- JaNicki (J.), SkUPin (J.) (1958). - Charakterystyka skladu chemicznego grzybni odpadowej Penicillium chrysogenum. Acta Microbiologica Polonica., 7, 139.

- JerusalimskiJ (N. D.), Konowa (I. W.) Neronowa (N. M.) (1959). - Opredielennije witaminow $\mathrm{i}$ antybiotykow sposobom difuzji $\mathrm{w}$ agar. Uproszczenije rascezetow pri czaszecznom metodie. Mikrobiologia, 28, 3, 433.

- Maslowski (P.) (1957). - Elektroforeza bibulowa aminokwasow przy zastosowaniu wysokich napiec. Pos. Biochem., 3, 335.

- Maslowski (P.) (1960). - Wysokonapieciowa elektrochromatografia bibulowa aminokwasow w roznych okresach-kielkowania Hordeum sativum. Roczn. Nauk Roln., 81-A-3, 561.

- Nesterowa (E. A.) (1967). - Metody opredilenija witaminow w kormach «Kolos » Moskwa.

- Owsiejczuk (W.) (1967). - Oznaczanie ilosciowe i jakosciowe mocznika w paszach. Medycyna Weterynaryjna., 23, 170.

- Painter (H. R.) (1954). - Factors affecting the growth of fungi asociated with sewage purification. J. Gen. Microb., 10, 177.

- Rhodes (R. A.), Hall (H. H.) and Anderson (R. T.) (1961). - Lisyne, metionine and tryptofan content of microorganisms. III Molds. Appl. Micobiol., 8,3. 